\title{
Diversity of Mosquito Fauna in different Habitats of District Dehradun, Uttarakhand
}

\author{
Iftikhar Ul Haq and Sundar Singh*
}

Department of Zoology, Entomology lab, D.A.V. (P.G.) College, Dehradun, Uttarakhand, India

*Corresponding author

Keywords

Aedes, Anopheles, mosquitoes,

Diversity, Shannon

Weiner index

Article Info

Accepted:

18 March 2021

Available Online:

10 April 2021
In the present study a total of 2822 specimens of 25 species of mosquitoes belonging to 6 genera viz., Anopheles, Culex, Aedes, Armigeres, Toxorhynchites and Uranotaenia from distt Dehradun between January 2019 to December 2020 were recovered. Of these, 12 species of Anopheles, 5 species each of Culex and Aedes were main species, in which Anopheles form $48.12 \%$, Culex $22.89 \%$ and Aedes $18.85 \%$ respectively. Shannon and Evenness index for Anopheles (2.212, 0.839) Culex (1.642, 0.746) and Aedes (1.625. 0.657) during entire study period were obtained. Overall highest Shannon index were 1.9358 during September 2020 and lowest 1.0781 during January 2020.

\section{Introduction}

India has rich biological diversity and one of the 12 mega diverse countries of the world (the biological diversity act, 2003). Diversity of insects is of great importance to the environmentalist as they are bio-indicators. Among the insects, mosquitoes are medically important group of insects and they transmit many vector borne disease (VBDs) like Malaria, Dengue, Chikungunya, Filariasis and Japanese Encephalitis (JE) in India. In the recent years, the distribution range of both mosquitoes and mosquito borne disease are proliferating in large number everywhere due to rapid urbanization, excessive deforestation and resistant among mosquitoes to pesticides, construction of dams and development of new agro-ecosystem (Edillo et al., 2004).

Earlier records of mosquitoes from Dehradun are shown by various workers (Theobald, 1902; Thomson, 1903 ; Christophers, 1916; Covell $(1927,1931)$ mentioned a list of 13 species of Anopheles in a monograph on the distribution of Anopheline mosquitoes in India. Since then there was almost no record of mosquitoes until 1957 from this region. 
Wattal et al., (1958) made observation on the mosquitoes from the Dehradun and collected 25 species of mosquitoes belonging to the seven genera. Rao et al., (1973) undertook the extensive survey of haematophagous arthropods including mosquitoes from western Himalayas and recorded 70 species of mosquitoes belonging to 8 different genera, of these 16 species belonged to genus Anopheles.

Thereafter, Bhat (1975), in a study on haematophagous arthropods in the Himalayan region recorded 63 species of mosquitoes under 10 genera.

An update list of the Tribe Aedini has been provided by Kaur (2003) which also included mosquito species from Garhwal including this region. Pemola and Jauhari (2004) while studying on mosquito record from Garhwal region (Uttaranchal) recorded 47 species of mosquitoes. In a survey for haematophagous insects occurring in different zones of district Dehradun (Uttarakhand) Pemola and Jauhari (2009) obtained 36 species of mosquitoes. After four year Pemola and Jauhari (2013) in a study on dipterous haematophagous insects occurring in Dehradun district and its adjoining areas in Uttarakhand, India recovered 38 species of mosquitoes.

Recently, Sadeura (2018) worked on mosquito diversity from kempty falls near mussoorie, Uttarakhad and found 20 species of mosquito belonging to four genera i.e. Aedes, Armigeres, Anopheles and Culex.

Keeping in view that an overview of mosquito faunal diversity is a necessary prelude for proper understanding of occurrence of a particular species at a particular time as well as for planning strategy for control of vectors borne diseases. Further, during the last 3-4 years there has been drastic changes in the climate due to rapid urbanization as a result of which an increase in dengue cases and other
VBDs. Hence, it is proposed to understand survey work towards mosquito occurrence in district Dehradun.

\section{Materials and Methods}

The sites selection for sampling purposes is based on the geographical division of the distt Dehradun as six blocks where 10 different sites were selected. In each sampling site, there were fixed collection spots while random sampling was also performed. Mosquitoes were sampled using aspirator and light trap (WHO, 1975), The identification of mosquitoes is based on adult characters using standard taxonomic keys and catalogues (Das et al., 1990; Nagpal and Sharma, 1995; Tyagi et al., 2015) and WHO, 2020). In certain cases, the immature forms were emerged into adults under laboratory conditions and then the species was identified.

\section{Data analysis}

Species diversity is represented through Species richness $(\mathrm{S})$, Shannon -wiener index $(\mathrm{H})$ and Shannon Evenness index (E) by the following formulae:

Species richness $(\mathrm{S})=$ Total number of species

Shannon index $(\mathrm{H})$

$$
=\sum_{\mathrm{i}=1}^{\mathrm{S}}-(\mathrm{Pi} * \text { in } \mathrm{Pi})
$$

Where

$\mathrm{H}=$ the Shannon diversity index

$\mathrm{Pi}=$ fraction of the entire population made up of a species $i$

$\mathrm{S}=$ numbers of species encountered

$\sum=$ Sum from species 1 to species $\mathrm{S}$ 
Shannon Evenness Index (E)

$=\mathrm{H} / \mathrm{In}(\mathrm{S})$

Where

$\mathrm{H}=$ Shannon diversity index

In $(S)=$ Natural logarithm of species richness (S)

\section{Results and Discussion}

A total of 2822 specimens of mosquitoes belonging to 25 species under 6 genera viz., Anopheles $(\mathrm{S}=12: \mathrm{n}=1358), \quad$ Culex $\quad(\mathrm{S}=05$ : $\mathrm{n}=646)$, Aedes $(\mathrm{S}=05: \mathrm{n}=532)$, Armigeres $(\mathrm{S}=01, \mathrm{n}=227)$, Toxorhynchites $(\mathrm{S}=01,: \mathrm{n}=52)$ and Uranotaenia $(\mathrm{S}=01, \mathrm{n}=07)$.were captured. Rank abundance showed the percentage of species abundance. Species in first rank being the most abundant, second being the second most abundance and so on (Table 1).

The most dominant mosquitoes were Anopheles (48.12\%) followed by Culex (22.89\%), Aedes (18.85\%), Armigeres (8.04\%), Toxorhynchites (1.84\%) and Uranotaenia $(0.25 \%)$ in succeeding order.

Genera wise Species diversity is represented through Species richness (S), Shannon Weiner index $(\mathrm{H})$ and Shannon Evenness Index (E) in Table 2. The species richness (S) and Evenness (E) were found as 12, 0.84; 05, 0.75 and 05, 0.66 for Anopheles, Culex and Aedes mosquitoes respectively. Highest Shannon index was shared by Anopheles (2.212) followed by Culex (1.642) and Aedes (1.625).

Overall, month wise the value of ShannonWiener index was found in the range of 1.0782 to 1.9348 and 1.0781 to 1.9358 during 2019 and 2020 respectively. The lowest value (1.0782) was recorded in December and the highest (1.9348) in September during 2019 and during 2020 the lowest value (1.0781) was recorded in January and highest value (1.9358) in September. The Shannon index showed high resemblance to each other during the study period for both the years. The values of Evenness index were between 0.9142 to 0.9944 and 0.9136 to 0.9846 during 2019 and 2020 respectively. The lowest value was recorded in September and highest value in March (Table 3).

Anopheles species showed higher species richness and greater species evenness than Culex species followed by Aedes species. The genera i.e. Armigeres, Toxorhynchites and Uranotaenia shared one species each.

Keeping in view the diversity of mosquitoes in district Dehradun, since, the studies made from this region were limited and was conducted by Pemola and Jauhari (2004, 2005, 2009 and 2013) and Sadeura (2018). Rao et al., (1973) and Bhat (1975) recorded 31 and 30 species of mosquitoes respectively under 4 genera. But, during the present study 25 species of mosquitoes have been recorded under six genera. There are marked difference in the composition of Anopheline mosquitoes as reported by various workers (Wattal et al., 1958; Kalra and Wattal, 1965; Bhat, 1975). The present observations are at variance with the studies made by Kalra and Wattal (1965) in not having An. aitkenii in the collection. Present study also shows similarity with the findings made by Jauhari et al., (1992) and Mahesh and Jauhari (2000) in respect of different mosquito species. Further various species of Anopheles recorded by them have not been found in the present study. From district Dehradun Pemola and jauhari (2009) obtained 36 species of mosquito but in present study only 25 species of mosquito were obtained. It is due to environmental change, increasing urbanization and other factors. So many mosquito species become disappear. 
Table.1 List of Mosquitoes collected from district Dehradun between January 2019 to December 2020.

\begin{tabular}{|c|c|c|}
\hline S.No & Name of Species & $\begin{array}{c}\text { Abundance } \\
\text { Rank }\end{array}$ \\
\hline A. & \multicolumn{2}{|l|}{ Anopheles } \\
\hline 1. & An. culicifacies (Giles, 1901) & 1 \\
\hline 2. & An. fluviatilis ( James, 1902) & 6 \\
\hline 3. & An. stephensi (Liston, 1901) & 2 \\
\hline 4. & An. subpictus ( Grassi , 1899) & 3 \\
\hline 5. & An. maculates (Theobald, 1901) & 4 \\
\hline 6. & An. aconitus (Doenitz, 1902) & 5 \\
\hline 7. & An. annularis ( Van der wulp, 1884) & 7 \\
\hline 8. & An. vagus (Deonitz, 1902) & 8 \\
\hline 9. & An. gigas ( Giles, 1901) & 9 \\
\hline 10. & An. minimus ( Theobald, 1901) & 10 \\
\hline 11 & An. splendidus ( Koidzumi, 1920) & 11 \\
\hline 12. & An. pulcherrimus (Theobald, 1902) & 12 \\
\hline B. & \multicolumn{2}{|l|}{ Culex } \\
\hline 1. & Cx. quinquefasciatus (Say, 1823) & 1 \\
\hline 2. & Cx. mimeticus $(\mathrm{Noe}, 1899)$ & 4 \\
\hline 3. & Cx. vishnui (Tjeobald, 1901) & 2 \\
\hline 4. & Cx. raptor (Edwards, 1922) & 3 \\
\hline 5. & Cx. ramakrishnii (Wattal and Kalra, 1965) & 5 \\
\hline C. & \multicolumn{2}{|l|}{ Aedes } \\
\hline 1. & Ae. aegypti (Linnaeus, 1762) & 1 \\
\hline 2. & Ae. albopictus (Skuse, 1894) & 2 \\
\hline 3. & Ae. vittatus (Bigot, 1861) & 3 \\
\hline 4. & Ae.pseudotaeniatus (Giles, 1901) & 4 \\
\hline 5. & Ae. albolateralis (Theobald, 1908) & 5 \\
\hline D. & \\
\hline 1. & \multicolumn{2}{|l|}{ Ar. Durhami (Edwards,1917) } \\
\hline E. & \multicolumn{2}{|l|}{ Toxorhynchites } \\
\hline 1. & \multicolumn{2}{|l|}{ T. splendens (Weidemann, 1819) } \\
\hline F. & \multicolumn{2}{|l|}{ Uranotaenia } \\
\hline 1. & U. nivipleura (Leicester, 1908) & \\
\hline
\end{tabular}


Table.2 Species diversity of the mosquitoes collected from district Dehradun.

\begin{tabular}{|c|c|c|c|c|}
\hline $\begin{array}{c}\text { Genera / } \\
\text { group }\end{array}$ & $\begin{array}{c}\text { S (Species } \\
\text { richness) }\end{array}$ & $\begin{array}{c}\text { E (Evenness } \\
\text { Index) }\end{array}$ & $\begin{array}{c}\text { H (Shannon } \\
\text { Index) }\end{array}$ & $\begin{array}{c}\text { N (No of } \\
\text { specimens) }\end{array}$ \\
\hline Anopheles & 12 & 0.839 & 2.212 & 1358 \\
\hline Culex & 05 & 0.746 & 1.642 & 646 \\
\hline Aedes & 05 & 0.657 & 1.625 & 532 \\
\hline
\end{tabular}

Table.3 Diversity indices of mosquito species in District Dehradun during January 2019 to December, 2020.

\begin{tabular}{|c|c|c|c|c|}
\hline Month & \multicolumn{2}{|c|}{$\mathbf{2 0 1 9}$} & \multicolumn{2}{c|}{2020} \\
\hline & H & E & H & E \\
\hline Jan. & 1.0791 & 0.9824 & 1.0781 & 0.9832 \\
\hline Feb. & 1.0796 & 0.9858 & 1.0784 & 0.9846 \\
\hline March & 1.6750 & 0.9966 & 1.6746 & 0.9908 \\
\hline April & 1.6760 & 0.9842 & 1.6766 & 0.9844 \\
\hline May & 1.7815 & 0.9944 & 1.7818 & 0.9938 \\
\hline June & 1.8216 & 0.9940 & 1.8224 & 0.9928 \\
\hline July & 1.8923 & 0.9912 & 1.8926 & 0.9922 \\
\hline Aug. & 1.8998 & 0.9706 & 1.8992 & 0.9712 \\
\hline Sep. & 1.9348 & 0.9142 & 1.9358 & 0.9136 \\
\hline Oct. & 1.8892 & 0.9768 & 1.8896 & 0.9772 \\
\hline Nov. & 1.7407 & 0.9902 & 1.7437 & 0.9958 \\
\hline Dec. & 1.0782 & 0.9822 & 1.0784 & 0.9820 \\
\hline
\end{tabular}

$\mathrm{H}=$ Shannon Weiner diversity index, $\mathrm{E}=$ Evenness diversity index

The result of present study is similar with the result observed in Taml Nadu (Kumar et al., 2011; Amala et al., 2011) and in Warangal urban environment (Suhasini and Sammaiah, 2014) all reported that most dominant species was Culex quinquefasciatus, Ades albopictus, Anopheles subpictus.

The biodiversity indices in terms of Shannon and evenness indices were also similar with other workers (Suhasini and Sammaiah, 2014; Tyagi and Pervez, 2018).

Based on present findings, many species are common, it is due to the fact that there could be certain climatic conditions, which establishes their adaptability best suited for growth and development.

\section{Acknowledgement}

We are thankful to the Head, department of zoology, D.A.V. (P.G.) College, Dehradun, Uttarakhand for providing laboratory facilities. We also thank CSIR (Govt of India) New Delhi for financial support.

\section{References}

Amala S., Rajendrabhoopathy S., Arunachalam N., Aunradha, V., 2011. A study on diversity of mosquitoes in Rajathanikottai village Dindigul District, Tamil Nadu, India. Annals of Biological Res, 2(6): 496-499.

Bhat H R., 1975. A survey of haematophagous Arthropods in Western Himalayas, 
Sikkim and hill districts of west Bengal: Records of mosquitoes collected from Himalayan region of Uttar Pradesh with ecological notes. Indian J Med Res., 63, 1583-1608.

Das B P., Rajagopal R., Akiyama J., 1990. Pictorial key to Indian Anopheline mosquitoes. Zoology, 2, 132- 162.

Edillo, F.E., Toure Y.T., Lanzaro G.C., Dolo G., Taylor C.E. 2004. Survivorship and Distribution of Immature Anopheles gambiaens s.l. (Diptera: Culicidae) in Banambani Village, Mali., J Med Entomol., 41(3): 333-339.

Jauhari R.K., Srivastava N., Singh R.P., Singh S., 1992. A note on the collection of mosquitoes from different habitations in peri-urban areas of Doon valley. Bioved, 3, 237-238.

Kalra N.L., Wattal B.L., 1965. An entomological survey of Dehradun valley (Uttar Pradesh) Part III. Addition to the records of mosquitoes of Doon valley. Bull Ind Soc Mal Com Dis., 2, 314- 317.

Kaur R., 2003. An update on the distribution of mosquitoes of the tribe Aedini in India (Diptera: Culicidae). Oriental insects, 37, 439-455.

Kumar K.R., Nattuthurai N., Annamalai M., 2011. Diversity of mosquito fauna in three selected sites of usilampatti taluk, Madurai district, Tamil Nadu. Elixir Bio Diver, 36A, 4064- 4066.

Mahesh R.K., Jauhari R.K., 2000. Resurgence of sylvatic mosquitoes in Doon valley. J Parasit Appl Anim Biol., 9, 9-16.

Nagpal B N., Sharma V P., 1995. Indian Anophelines. Oxford \& IBH Publishing Co. Pvt Ltd Mohan Primlani, N. Delhi, pp., 1- 416.

Pemola Devi N., Jauhari R.K., 2004. Mosquito records from Garhwal Region (Uttaranchal). J Exp Zool India., 7 (2): 237-244.

Pemola Devi N., Jauhari., 2009. Survey for haematophagous insects occurring in different zones of district Dehradun (Uttarakhand. J. Ent Res., 33(2) : 149156.

Pemola Devi N., Jauhari., R.K. 2013. Dipterous haematophagous insects occurring in Dehradun district and its adjoin areas in Uttarakhand, India. Tropical Biomedicine, 30 (4) : 608-614

Sadeura J.K., 2018. Mosquito diversity from Kempty falls, near Mussoorie, Uttarakhand (India), Int J Zoology studies, 3(2) : 160-162.

Suhasini G., Sammaiah Ch., 2014. Diversity of mosquitoes (Diptera: Culicidae) in different habitats of Warrangal urban environment. J Ent and Zoology Studies. 2(4) : 7-10.

Theobald F.V. 1902. A short description of the culicidae of India, with description of new species of Anopheles. Proceedings of the Royal Society of London, $69: 367-394$.

Thomson F. W., 1903. Notes on the Culicidae of Dehradun. J Trop Med., 6, 314- 315.

Thomson F. W., 1909 Mosquitoes and malaria in Dehradun, India. J Roy Army Med Corps., 12, 502- 508.

Tyagi B.K., Munirathinam A., Venkatesh A., 2015. A Catalogue of Indian mosquito. Int J Mosq Res. 2(2) : 50-97.

Tyagi M., Pervez, A., 2018. Diodiversity and seasonal prevalence of mosquitoes from Terai region of Uttarakhand. J Bio Innov., 7 (4) : 503-510.

Wattal B. L., Kalra N. L., 1961. Region wise pictorial keys to the female Indian Anopheles. Bull Nat Soc Ind Mal Mosq Borne Dis., 9, 85-138.

Wattal B. L., Kalra N L. 1965. An entomological survey of Dehradun valley (U.P.) Part II. Description of Culex (Culiciomyia) ramakrishnii sp. n. and allotype male of Uraeotaenia maculipleura Leicester, 1908. Bull Ind Soc Mal Com Dis., 2, 309-313. 
Wattal B. L., Bhatia M. L., Kalra N. L., 1958. Some new records of Culicines of Dehradun (U.P.) with a description of new variety. Indian J Malariol., 12, 217- 230.

WHO, 1975. Mannual on practical entomology in malaria vector bionomics and organization of antimalaria activities Part I and Part II, offset Publications, Geneva.

WHO, 2020. Pictorial identification key of important disease vectors in the WHO South east Asia region. Pp 1-79

\section{How to cite this article:}

Iftikhar U1 Haq and Sundar Singh. 2021. Diversity of Mosquito Fauna in different Habitats of Distt Dehradun, Uttarakhand. Int.J.Curr.Microbiol.App.Sci. 10(04): 583-589.

doi: https://doi.org/10.20546/ijcmas.2021.1004.058 